\title{
ST
}

Science \& Technology

PAPER - OPEN ACCESS

\section{Analisis Buku Penuntun Praktikum Kimia Kelas XII Semester I Berdasarkan Kurikulum 2013}

\author{
Author : Zainal Arifin dkk., \\ DOI $\quad: 10.32734 /$ st.v2i1.352 \\ Electronic ISSN $\quad: 2654-7082$ \\ Print ISSN : $2654-7074$
}

Volume 2 Issue 1 - 2018 TALENTA Conference Series: Science \& Technology (ST)

This work is licensed under a Creative Commons Attribution-NoDerivatives 4.0 International License.

Published under licence by TALENTA Publisher, Universitas Sumatera Utara

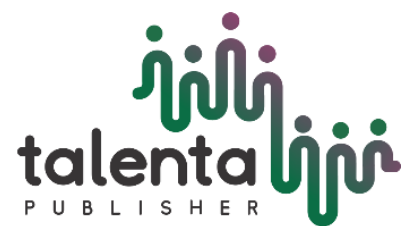




\title{
Analisis Buku Penuntun Praktikum Kimia Kelas XII Semester I Berdasarkan Kurikulum 2013
}

\author{
Zainal Arifin $^{\mathrm{a} *}$, Febri Yanti ${ }^{\mathrm{b}}$, Ramlan Silaban ${ }^{\mathrm{b}}$, Simson Tarigan $^{\mathrm{c}}$ \\ ${ }^{a, b}$ Mahasiswa Magister Pendidikan Kimia, Program Pascasarjana, Universitas Negeri Medan, Sumatera Utara, Indonesia \\ ${ }^{c, d}$ Dosen Magister Pendidikan Kimia, Program Pascasarjana, Universitas Negeri Medan, Sumatera Utara, Indonesia \\ *zachemistry@gmail.com
}

\begin{abstract}
Abstrak
Sistem Kurikulum 2013 menuntut siswa untuk berperan aktif dalam proses pembelajaran di sekolah maupun belajar secara mandiri. Sehingga perlu adanya media pembelajaran yang dapat membantu siswa dalam memahami pembelajaran kimia. Kimia merupakan ilmu alam yang bersifat sebagai produk dan konsep sehingga dalam pembelajarannya dapat dilakukan melalui kegiatan praktikum. Kegiatan praktikum dibutuhkan suatu perangkat sebagai panduan dalam kerja ilmiah yang disebut buku penuntun praktikum. Desain penelitian yang digunakan adalah Research and Development (R \& D)model ADDIE (analysis, design, development, implementation, dan evaluation).Penelitian ini hanya dilakukan pada tahap awal yaitu analisis buku penuntun praktikum. Hasil yang diperoleh adalah gambaran awal buku penuntun praktikum yang sudah ada untuk dilakukan pengembangan lebih lanjut menjadi produk buku penuntun praktikum kimia inovatif sesuai kurikulum 2013.
\end{abstract}

Kata Kunci: penuntun praktikum, pembelajaran kimia, media pembelajaran, kurikulum 2013

\section{Pendahuluan}

Saat ini telah diberlakukannya Kurikulum 2013 yang mana model pembelajaran dengan pendekatan saintifik dengan lima langkah pembelajaran, yaitu: mengamati, bertanya, menalar, mencoba, dan mengkomunikasikan. Salah satu pembelajaran yang menerapkan lima langkah pembelajaran adalah pelajaran kimia. Ilmu kimia merupakan experimental science, tidak dapat dipelajari hanya melalui membaca, menulis atau mendengarkan saja. Mempelajari ilmu kimia bukan hanya menguasai kumpulan pengetahuan berupa fakta, konsep, prinsip saja tetapi juga merupakan suatu proses penemuan dan penguasaan prosedur atau metode ilmiah. Oleh karena itu dalam mempelajari ilmu kimia ada dua hal penting yang harus diperhatikan, yakni kimia sebagai produk temuan para ilmuan berupa fakta, konsep, prinsip, hukum, teori dan kimia sebagai proses berupa kerja ilmiah [1]. Kerja ilmiah dalam sains memiliki tujuan untuk melakukan keterampilan, mengembangkan dan pemahaman terhadap sains dan pemahaman tentang proses penyelidikan ilmiah [2].

Sejalan dengan pendapat di atas Tezcam dan Bligin [3] menyatakan perumpamaan mengenai pembelajaran kimia, bahwa seseorang yang belajar menggambar, namun tanpa menggunakan cat dan kanvas atau seseorang yang mencoba belajar bersepeda, namun tanpa menggunakan sepeda sama halnya dengan seseorang yang belajar kimia tanpa melakukan praktikum. Hal ini berarti bahwa pembelajaran kimia paling efektif dapat dilakukan melalui kegiatan praktikum. Praktikum yang dilakukan siswa dapat meningkatkan pengetahuan faktual dan prosedural serta memudahkan dalam memahami pembelajaran kimia [4]. Penggunaan strategi pembelajaran laboratorium menciptakan dan meningkatkan motivasi, minat, dan prestasi siswa [5], berfikir kritis untuk mengembangkan kemampuan kognitif dan keterampilan [6]. 
Penggunaan laboratorium kimia dalam pembelajaran akan memberikan pengalaman langsung untuk mengembangkan kompetensi agar mampu menjelajahi dan memahami alam sekitar secara ilmiah serta akan memberikan pengalaman untuk dapat mengajukan dan menguji hipotesis melalui percobaan, merancang dan merakit instrumen percobaan, mengumpulkan, mengolah, dan menafsirkan data, menyusun laporan, serta mengkomunikasikan hasil percobaan secara lisan dan tertulis. Pernyataan tersebut didukung oleh Can [7] yang menyatakan bahwa dalam pekerjaan laboratorium, siswa didorong untuk berpartisipasi dalam kegiatan ilmiah mulai dari belajar melalui pengalaman dan penemuan, mengajukan pertanyaan, menyarankan solusi, membuat prediksi, mengatur data hingga menjelaskan melalui contoh. Sehingga diperlukan adanya penyediaan alat dan bahan praktikum dan pengelolaan laboratorium yang baik, agar pelaksanaan pembelajaran kimia dapat berjalan secara maksimal [8]. Kegiatan praktikum merupakan kegiatan pembelajaran yang dapat dilakukan dikelas maupun dilaboratorium [9].

Penggunaan metode praktikum akan efektif jika didukung oleh ketersediaan alat dan bahan kimia di laboratorium serta keterampilan guru dalam pelaksanaan praktikum. Namun pada kenyataannya pembelajaran praktikum disekolah banyak memiliki kendala-kendala dalam pelaksanaannya. Alternatif lain menurut Tatli dan Ayas [10] dapat menggunakan laboratorium virtual untuk mengatasi kendala-kendala dalam pelaksanaan praktikum di sekolah.

Kendala lain dijelaskan oleh Tuysuz [11]diantaranya belum tersedianya penuntun praktikum kimia yang dapat mengarahkan siswa ketika praktikum, guru juga belum memiliki panduan dalam menilai keterampilan proses dan sikap ilmiah. Bahan dan alat praktikum kimia yang mahal juga menjadi kendala dalam pelaksanaan praktikum kimia disekolah. Menurut Lubis dkk [12], pelaksanaan kegiatan praktikum membutuhkan penuntun praktikum, dimana penuntun praktikum digunakan untuk mempermudah menemukan langkah-langkah praktikum. Selain itu, penuntun praktikum juga harus mampu mengembangkan kemampuan belajar ilmiah serta keterampilan proses para peserta didik.

Penuntun praktikum kimia yang telah digunakan disekolah maupun penuntun praktikum kimia yang dikembangkan di pascasaerjana Universitas Negeri Medan masih memiliki beberapa kendala dalam penggunaannya, diantaranya penuntun praktikum masih sulit untuk dipahami oleh siswa dan tidak menyediakan bahan dan alat yang sederhana yang dapat menjadi alternatif bagi sekolah yang tidak memiliki laboratorium.

Berdasarkan latarbelakang yang dikemukakan diatas, maka tujuan dari penelitian ini adalah menganalisis penuntun praktikum yang digunakan disekolah dan penuntun praktikum kimia yang dikembangkan di pascasarjana universitas negeri medan. Sehingga, dari analisis penuntun tersebut dapat memperoleh gambaran terhadap penuntun yang sudah ada untuk dikembangkan menjadi produk penuntun praktikum kimia yang inovatif.

\section{Metode Penelitian}

Analisis buku penuntun praktikum kimia kelas XII semester I berdasarkan Kurikulum 2013 menggunakan desain penelitian yang digunakan adalah Research and Development ( $\mathrm{R} \& \mathrm{D})$ model ADDIE (analysis, design, development, implementation, dan evaluation). Penelitian ini hanya dilakukan pada tahap awal yaitu analisis buku penuntun praktikum.

Jenis data yang diperoleh dalam analisis buku penuntun ini berupa data kualitatif dan kuantitatif. Data kualitatif berupa komentar, saran ataupun kritik terhadap buku penuntun praktikum yang dianalisis. Sedangkan data kuantitatif berupa angka-angka yang diperoleh berdasarkan lembar validasi analisis buku penuntun praktikum dengan menggunakan skala Likert $(4,3,2,1)$. Instrumen pengumpulan data yang digunakan dalam penelitian ini berupa lembar validasi terhadap buku penuntun praktikum A, B, dan C berdasarkan standar BSNP (Badan Standar Nasional Pendidikan). Teknik analisis data yang digunakan untuk menganalisis data hasil validasi buku penuntun praktikum adalah teknik perhitungan rata-rata.Menurut Arikunto [13] rentang kriteria validasi terhadap hasil perhitungan secara lengkap dapat diamati pada Tabel 1. 
Tabel 1. Kriteria Validasi Buku Penuntun Praktikum

\begin{tabular}{lcc}
\hline No & Rata-rata & Kriteria variabel \\
\hline 1 & $3,26-4,00$ & Sangat valid dan dapat digunakan \\
2 & $2,51-3,25$ & Valid dan dapat digunakan \\
3 & $1,76-2,50$ & Kurang valid perlu di Revisi \\
4 & $1,00-1,75$ & Tidak valid perlu direvisi total \\
\hline
\end{tabular}

\section{Hasil dan Pembahasan}

Sebelum melakukan inovasi penuntun praktikum. Peneliti melakukananalisis terhadap buku penuntun yang beredar di sekolah maupun yang telah dikembangkan pada penelitian sebelumnya yang dilakukan di Program Studi Magister Pendidikan Kimia Program Pascasarjana Universitas Negeri Medan. Adapun penuntun praktikum yang di analisis terdiri dari 4 bagian yaitu kelayakan isi, kelayakan bahasa, kelayakan penyajian dan kelayakan kegrafikan. Berdasarkan hasil validasi maka diperoleh bahwa buku penuntun praktikum A, B dan C dapat dikatakan sangat valid dan dapat digunakan. Hasil Validasi terhadap buku penuntun praktikum A, B dan C dapat dilihat pada gambar 1.

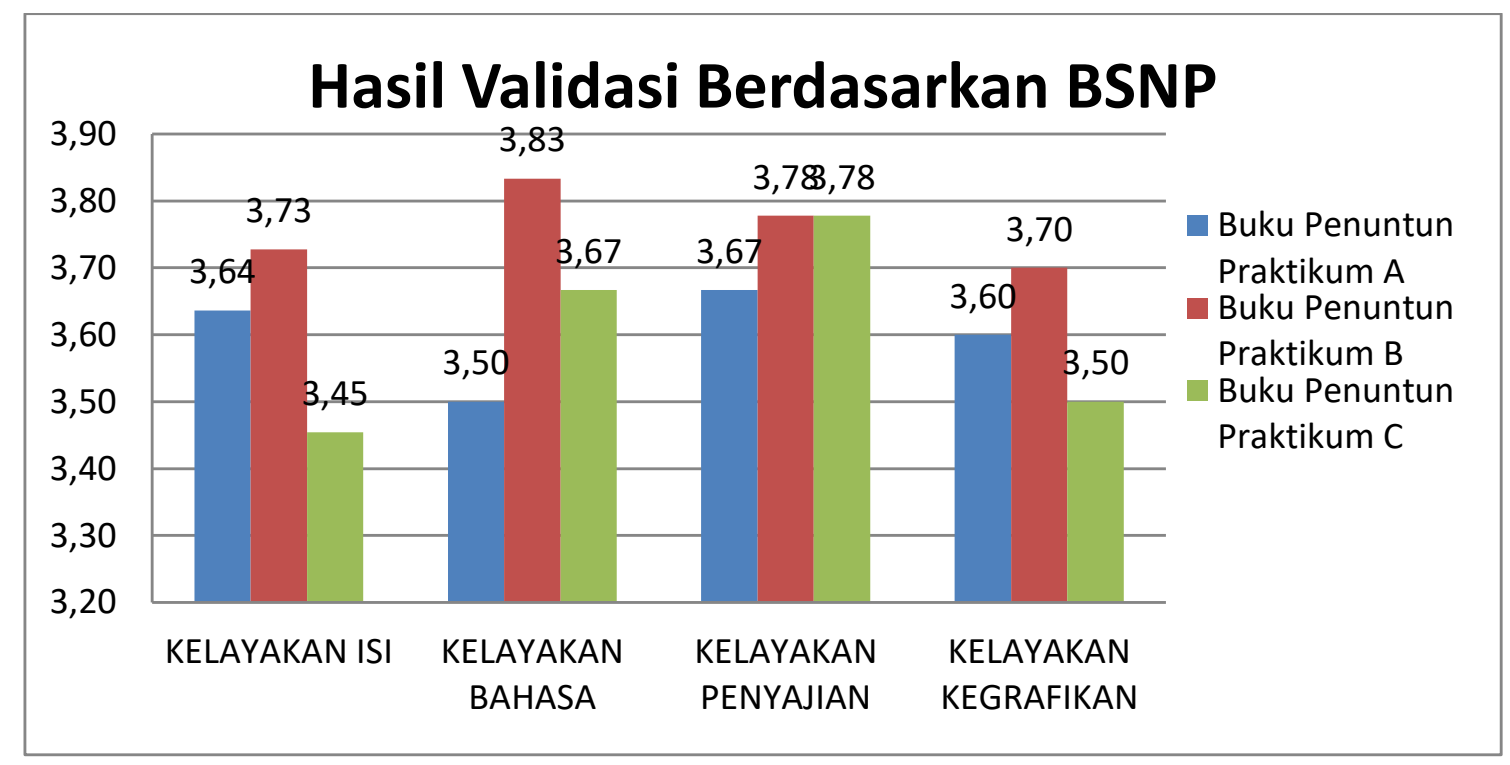

Gambar 1. Hasil Validasi Penuntun Praktikum A,B dan C

Hasil analisis terhadap kelayakan isi menyatakan bahwa buku penuntun praktikum yang dianalisis telah valid dan dapat digunakan. Namun masih terdapat beberapa yang harus di perbiki pada kelayakan isi diantaranya adalah kedalaman materi perlu disesuaikan kembali dengan bahan ajar, kesesuaian sub materi dalam penuntun praktikum dengan konsep dan penambahan tujuan pembelajaran pada tiap kegiatan praktikum. Validasi kelayakan isi dapat dilihat pada gambar 2 . 


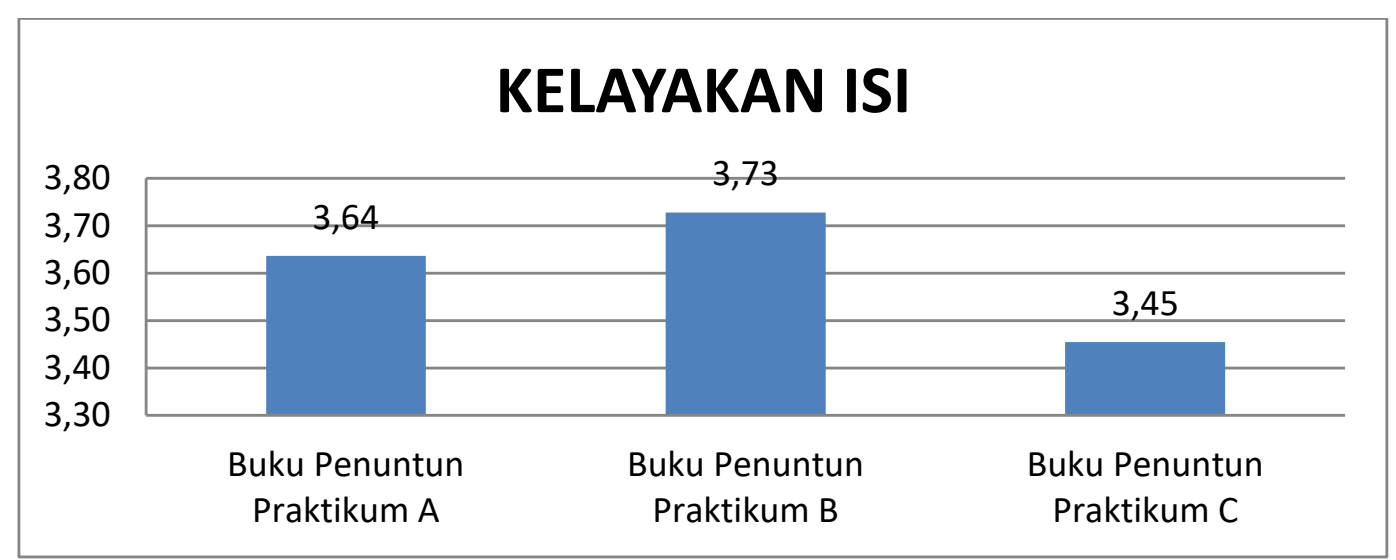

Gambar 2. Hasil validasi kelayakan isi buku penuntun praktikum A, B dan C

Hasil analisis terhadap kelayakan bahasa menyatakan bahwa buku penuntun praktikum yang dianalisis telah valid dan dapat digunakan. Namun dengan menyesuaikan kalimatyang menyertai suatu gambar atau ilustrasi agar terlihat lebih jelas. Validasi kelayakan bahasa dapat dilihat pada gambar 3.

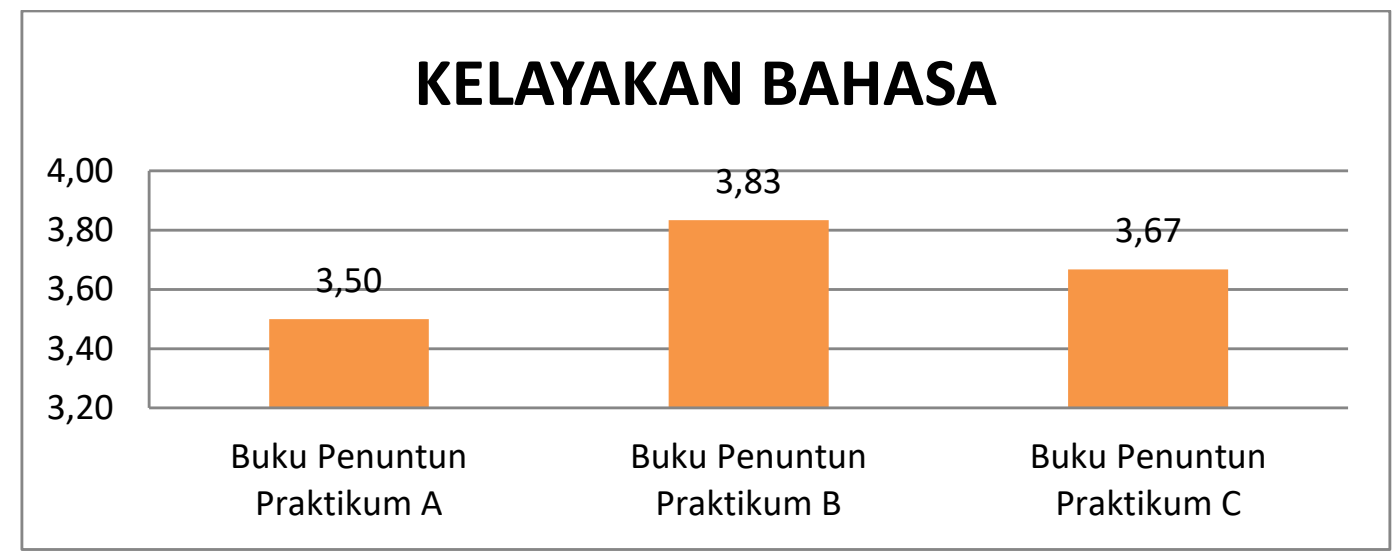

Gambar 3. Hasil validasi kelayakan isi buku penuntun praktikum A, B dan C

Hasil analisis terhadap kelayakan penyajian menyatakan bahwa buku penuntun praktikum yang dianalisis telah valid dan dapat digunakan. Namun dengan memperbaiki desain sampul dan desain keseluruhan penuntun praktikum agar menarik minat siswa. Validasi kelayakan penyajian dapat dilihat pada gambar 4.

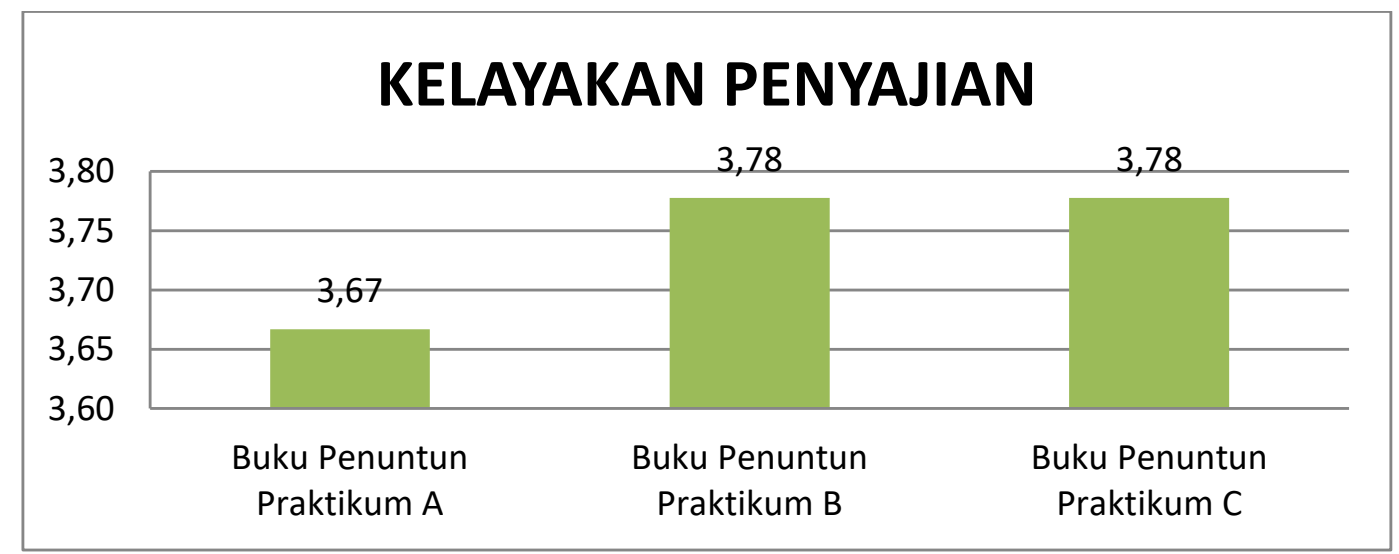

Gambar 4. Hasil validasi kelayakan isi buku penuntun praktikum A, B dan C 
Hasil analisis terhadap kelayakan kegrafikan menyatakan bahwa buku penuntun praktikum yang dianalisis telah valid dan dapat digunakan. Namun dengan memperbaiki ukuran buku agar sesuai dengan standar ISO. Validasi kelayakan kegrafikan dapat dilihat pada gambar 5.

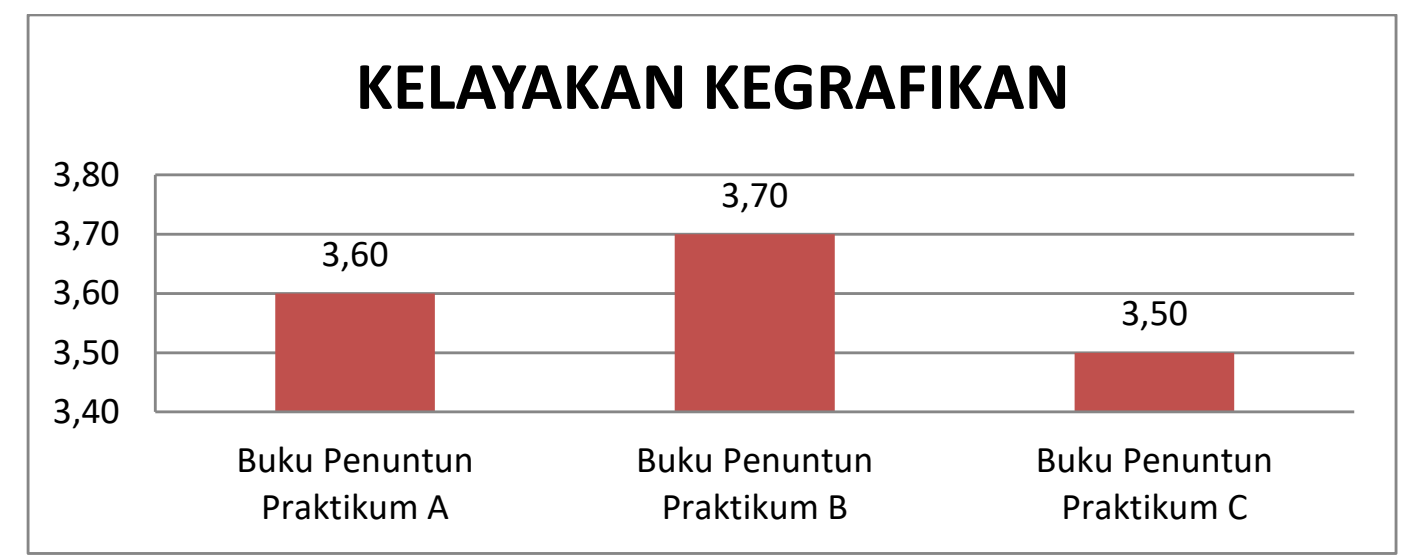

Gambar 5. Hasil validasi kelayakan isi buku penuntun praktikum A, B dan C

Setelah diperoleh hasil analisis buku penuntun praktikum maka selanjutnya dapat dilakukan pengembangan terhadap buku penuntun praktikum yang inovatif sesuai dengan kurikulum 2013. Adapun perbandingan komponen yang terdapat dalam inovasi buku penuntun praktikum kimiasesuai kurikulum 2013 dengan buku penuntun yang dianalisis dapat diluhat pada tabel 2 .

Tabel 2.Rencana Pengembangan Penuntun Praktikum KimiaInovatif sesuai Kurikulum 2013

\begin{tabular}{|c|c|c|c|c|c|}
\hline No & Komponen & $\begin{array}{c}\text { Penuntun } \\
\text { Praktikum } \\
\text { Inovasi }\end{array}$ & $\begin{array}{c}\text { Buku Penuntun } \\
\text { A }\end{array}$ & $\begin{array}{c}\text { Buku } \\
\text { Penuntun } \\
\text { B }\end{array}$ & $\begin{array}{c}\text { Buku } \\
\text { Penuntun } \\
\text { C }\end{array}$ \\
\hline 1. & Petunujuk Umum Penuntun & $\mathrm{v}$ & $\mathrm{v}$ & $\sqrt{ }$ & $\sqrt{ }$ \\
\hline 2. & Tata tertib Praktikum & $v$ & $v$ & $v$ & v \\
\hline 3. & Keselamatan kerja & $v$ & $v$ & $v$ & v \\
\hline 4. & Alat dalam laboratorium & $v$ & $v$ & $v$ & $\sqrt{ }$ \\
\hline 5. & Lambang bahaya dalam laboratorium & $v$ & $v$ & $v$ & v \\
\hline 6. & Prosedur penanganan limbah & $v$ & - & $v$ & $\sqrt{ }$ \\
\hline 7. & Analisis Kurikulum & $v$ & $v$ & $v$ & $\sqrt{ }$ \\
\hline 8. & Model pembelajaran berbasis proyek* & $v$ & - & $\sqrt{ }$ & v \\
\hline 9. & Kegiatan praktikum inovatif* & v & - & $v$ & v \\
\hline 10. & Lembar penilaian observasi sikap* & $v$ & - & - & - \\
\hline 11. & Lembar penilaian ketampilan praktikum* & $v$ & - & - & - \\
\hline 12. & Format penulisan laporan praktikum & $v$ & 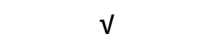 & $v$ & $\sqrt{ }$ \\
\hline 13. & Sistem periodik unsur* & $v$ & - & - & - \\
\hline
\end{tabular}

Keterangan: ${ }^{*}=$ inovasi yang terdapat dalam penuntun praktikum

Penuntun praktikum yang di inovasikan memuat beberapa komponendiantaranya: peraturan dasar di laboratorium, petunjuk keamanan dan keselamatandi laboratorium, pertolongan pertama pada kecelakaan di laboratorium, berbagaitanda yang sering dijumpai di laboratorium, prosedur penanganan limbah danbeberapa alat yang sering digunakan di labortorium, analisis kurikulum, sintakpembelajaran, dasar teori praktikum, 
kegiatanpraktikum, lembar observasi penilaian sikap, lembar penilaian keterampilan tespraktek, format penulisan laporan praktikum, daftar pustaka, identifikasikerusakan alat-alat praktikum, identifikasi bahan kimia berbahaya, tingkat skala bahaya bahan kimia dan sistem periodik unsur.

\section{Kesimpulan}

Buku penuntun praktikum kimia kelas XII semester I yang dianalisis terdiri dari 4 bagian yaitu kelayakan isi, kelayakan bahasa, kelayakan penyajian dan kelayakan kegrafikan. Berdasarkan pembahasan diatas, maka buku yang telah di analisis telah layak untuk digunakan namun masih terdapat beberapa hal yang harus dikembangkan mengingat buku penuntun yang dianalisis masih menggunakan kurikulum KTSP sehingga perlu adanya pengembangan sesuai dengan kurikulum 2013. Hasil yang diperoleh adalah gambaran awal buku penuntun praktikum yang sudah ada untuk dilakukan pengembangan lebih lanjut menjadi produk buku penuntun praktikum kimia inovatif sesuai kurikulum 2013.

\section{Referensi}

[1] Jahro, I.S dan Susilawati 2009. Analisis Penerapan Metode Praktikum pada Pembelajaran Ilmu Kimia di Sekolah Menengah Atas. Jurnal Pendidikan Kimia, 1(4): 20-26.

[2] Anza, M., Bibiso, M., Mohammad, A., and Kuma, B., 2016. Assessment of Factors Influencing Practical Work in Chemistry: A Case of Secondary Schools in Wolaita Zone, Ethiopia. I.J. Education and Management Engineering, 6: 53-63.

[3] Tezcam, H and Bilgin, E. 2004. Affects of Laboratory Method and Other Factors on The Students Success in The Teaching of The Vation Subject at The High School. The Journal of Gazi Educational Faculty, 24: 175-191.

[4] Xu, H. \& Talanguer, V. 2013. Effect of The Level of Inquiry of Lab Experiments on General Chemistry Students Written Reflections. Journal of Chemical Education, 90: 21-28.

[5] Okam, C.C and Zakari, I.I., 2017. Impact of Laboratory-Based Teaching Strategy on Students' Attitudes and Mastery of Chemistry in Katsina Metropolis", Katsina State, Nigeria.International Journal Of Innovative Research \& Development, 6(1):112-121.

[6] Alkan, F and Kocak, K., 2015. Chemistry laboratory applications supported with simulation. Procedia - Social and Behavioral Sciences, 176: 970 - 976.

[7] Can, Sendil., 2013. Pre-service science teachers' concerns about chemistry laboratory (case of mugla University-Turkey). Procedia - Social and Behavioral Sciences, 106: 2102-2111.

[8] Darsana, I.W., Sadia, I.W., Tika, I.N., 2014. Analisis Standar Kebutuhan Laboratorium Kimia dalam Implementasi Kurikulum 2013 Pada SMA Negeri Di Kabupaten Bangli. e-Journal Program Pascasarjana Universitas Pendidikan Ganesha, 4.

[9] Copriady, J., 2015. Practical Implementation of Practical Among Secondary School Teachers, Asian Journal of Scientific Research, 8(1): 2240.

[10] Tatli, Z \& Ayas, A. 2013. Effect of a Virtual Chemistry Laboratory on Students' Achievement. Educational Technology \& Society, 16(1): $159-170$.

[11] Tuysuz, C. 2010. The Effect of the virtual laboratory on students' achievement and attitude in chemistry. International Online Journal of Educational Sciences, 2(1): 37-53.

[12] Lubis, L.T., Silaban, R., Jahro, I.S., 2016. Pengembangan Penuntun Praktikum Kimia Dasar I Terintegrasi Pendekatan Inkuiri. Jurnal Pendidikan Kimia, 8(2): 20-30.

[13] Arikunto, S., (2010). Prosedur Penelitian Suatu Pendekatan Praktik. Jakarta: PT. Rineka Cipta. 